\title{
Health Data, Information, and Knowledge Sharing for Addressing the COVID-19
}

\author{
Lina F. Soualmia ${ }^{1,2}$, Kate Fultz Hollis ${ }^{3}$, Fleur Mougin ${ }^{4}$, Brigitte Séroussi' ${ }^{2,5}$ \\ 1 Normandie Université, Univ. Rouen, TIBS-LITIS EA 4108, Roven, France \\ 2 Université Sorbonne Paris Nord, INSERM UMR S1142, LIMICS, Paris, France \\ ${ }^{3}$ Oregon Health \& Science University Department of Biomedical Informatics and Clinical \\ Epidemiology, Portland, Oregon, USA \\ ${ }^{4}$ Univ. Bordeaux, INSERM, BPH, U1219, Bordeaux, France \\ ${ }^{5}$ Assistance Publique - Hôpitaux de Paris, Hôpital Tenon, Paris, France
}

\begin{abstract}
Summary
Objectives: To introduce the 2021 International Medical Informatics Association (IMIA) Yearbook by the editors.

Methods: The editorial provides an introduction and overview to the 2021 IMIA Yearbook whose special topic is "Managing Pandemics with Health Informatics - Successes and Challenges". The Special Topic, the keynote paper, and survey papers are discussed. The IMIA President's statement and the IMIA dialogue with the World Health Organization are introduced. The sections' changes in the Yearbook Editorial Committee are also described. Results: Health informatics, in the context of a global pandemic, led to the development of ways to collect, standardize, disseminate and reuse data worldwide: public health data but also information from social networks and scientific literature. Fact checking methods were mostly based on artificial intelligence and natural language processing. The pandemic also introduced new challenges for telehealth support in times of critical response. Next generation sequencing in bioinformatics helped in decoding the sequence of the virus and the development of messenger ribonucleic acid (mRNA) vaccines.

Conclusions: The Corona Virus Disease 2019 (COVID-19) pandemic shows the need for timely, reliable, open, and globally available information to support decision making and efficiently control outbreaks. Applying Findable, Accessible, Interoperable, and Reusable (FAIR) requirements for data is a key success factor while challenging ethical issues have to be considered.
\end{abstract}

\section{Keywords}

Medical Informatic, health information technology, IMIA Yearbook of Medical Informatics, COVID-19, pandemic

Yearb Med Inform 2021:4-7

http://dx.doi.org/10.1055/s-0041-1726541

\section{Biomedical Informatics as a Support for Managing Pandemics and Infodemics}

As we very slowly come back to work and try to live like we did before January 2020, the International Medical Informatics Association (IMIA) editorial team wishes for a happy return for all of us who have worked so hard to be safe for our colleagues, patients, and families. We hope to end the 2020-2021 pandemic that has disrupted our social activities, family events, research projects, and taken away so many lives. At the time of writing this editorial, we thought that we were done with the virus, but it is clear that the pandemic continues to impact the world. The severe acute respiratory syndrome coronavirus 2 (SARS-CoV-2), a ribonucleic acid (RNA) virus that causes the Corona Virus Disease 2019 (COVID-19), is rapidly mutating during replication and co-infections. Several epidemiological investigations and sequence-based surveillance worldwide have led to the identification of variants of concern B.1.1.7 (Alpha) [1], B.1.351 (Beta), B.1.617.2 (Delta), and P.1 (Gamma). But as Aristotle says though, "it is during our darkest moments that we must focus to see the light," and we all have tried to produce the best that we can even in restrictive and frightful conditions.

The theme of the $30^{\text {th }}$ edition of the International Medical Informatics Association (IMIA) Yearbook is "Managing Pandemics with Health Informatics - Successes and
Challenges". As noted by the co-editors of the IMIA Yearbook Special Topic section, Brian Dixon and John Holmes, "the best papers on managing pandemics with health informatics in 2020 represent only a fraction of the strong scientific articles relevant to this topic" [2]. The special section focuses on articles related to COVID-19 and the pandemic in the fields of public health and epidemiology, and shows the incredible efforts the medical informatics community made in keeping communities safe and finding good ways to show disease indicators (e.g., Reeves et al. [3] describe health informatics supporting COVID-19 response, and the other best papers selected in this $30^{\text {th }}$ edition give examples).

Coined in 2003, the "infodemic" concept has added a renewed interest in conjunction with the COVID-19 pandemic. The general definition of infodemic states that it "... is a blend of 'information' and 'epidemic' that typically refers to a rapid and far-reaching spread of both accurate and inaccurate information about something, such as a disease. As facts, rumors, and fears mix and disperse, it becomes difficult to learn essential information about an issue" [4]. Open collaborative approaches and the application of Findable, Accessible, Interoperable, and Reusable (FAIR) requirements can improve trust in data. The Keynote paper by Basit et al. [5] discusses data quality, obstacles to data collection, lessons learned, and ethical and privacy considerations related to pandemic data (such as contact tracing issues). 


\section{Highlights of the 30th Edition of the IMIA Yearbook}

Be sure to read the chapter on the History of Medical Informatics of this year's Yearbook. Casimir Kulikowski provides a historical overview of biomedical information and healthcare practices related to past pandemics. This very well documented chapter addresses data infrastructure and information and communication systems needed to deal with the pandemic. COVID-19 was the first major pandemic in world history where genomics and related biosciences - supported by biomedical informatics - were essential to decode the viral sequence data and to produce mRNA vaccines [6].

Check out some of the interesting mapping of terms related to Consumer Health Informatics $(\mathrm{CHI})$ in this year's $\mathrm{CHI}$ section. As CHI co-editors, Annie Lau and Pascal Staccini, discovered in the search for best papers related to the pandemic, health informatics consumers and social media faced a new context with worldwide information challenges to manage a new infectious disease such as the use of social listening to trace the dissemination of the disease and to assess patient experience for describing unknown clinical facts [7].

One of the best papers in the Decision Support (DS) section introduced a clinical decision support system for assessing the risk of a severe COVID-19 for patients at hospital admission. Wu et al. [8] built their model from an international multicenter study including retrospective and prospective cohorts from China, Italy, and Belgium. As noted by DS section co-editors Damian Bordolla and Grégoire Ficheur, the very early conduct of this large-scale multicenter study during the epidemic and the success of the model were encouraging and important [9].

Weemaes et al. described the need and the development of a laboratory management information system to cope with the extra workload of COVID-19 testing [10]. The co-editors of the Clinical Information Systems (CIS) section, Werner Hackl and Alexander Hoerbst, pointed out in their synopsis that $10 \%$ of the 500 most relevant terms appearing in the titles and abstracts of the CIS articles were related to the COVID-19 pandemic [11].
Among the three best papers selected by the Natural Language Processing (NLP) section, the paper by Poerner et al. presented a new energy-efficient transformer model, applied in particular to perform question-answering about COVID-19 [12] As underlined by Natalia Grabar and Cyril Grouin, the co-editors of the NLP section, much work has been done this year in the NLP field on COVID-19, including the development of a dedicated corpus and the use of patient data, scientific literature, and social networks to predict or analyse COVID-19-related events [13].

In the survey paper of the Health Information Management (HIM) section, Massoudi \& Sobolevskaia conducted a state of the art review of the research works published in response to the pandemic to highlight the challenges and obstacles posed by COVID-19 in this field [14]. Through the various themes addressed in the hundred or so articles they analysed, the authors identified the barriers that remain to be overcome and proposed recommendations to ensure that the discipline is ready in the event of a new pandemic.

Selected as a best paper within the Special Section, Reeves et al. published the first description of healthcare informatics supporting a rapid COVID-19 response from a health system [3]. For the Yearbook and the CIS section in particular, Reeves et al. have carried out a comprehensive review of published articles in the field of CIS to respond to the COVID-19 pandemic [15]. They identified more than 200 articles related to this topic and classified them into nine categories, including data sharing and interoperability, epidemiology reporting, telehealth and diagnosis testing.

Verspoor has produced an interesting survey paper in which she proposes to adopt a new model: a global learning health system (as discussed in the 2017 Yearbook special topic [16]), that is essential in the context of a worldwide pandemic [17]. This circular model is fed with observations made during the management of patients in clinical practice to enrich health-related knowledge, which in turn is needed to improve clinical practice. The author then described the work that has been implemented this year in Knowledge Representation and
Management (KRM) in the context of the COVID-19 pandemic and which can contribute to the implementation of this global learning health system.

Tilahun et al. in their survey for the Special Topic section showed the successes of digital health technologies as support for prevention and control of the COVID-19 [18]. Telehealth, mobile health (mHealth), internet of things (IoT), and electronic health records among others, combined with artificial intelligence, big data technologies, and prediction models, were used in multiple ways. This includes screening and management of patients, methods to minimize exposure, modelling of disease spread, and supporting overworked providers. Digital health technologies in response to the COVID-19 pandemic were principally used for the early test, report, isolation, treatment, exchanging information, remote consulting, reducing the overcrowding of health care facilities, and model prediction of the COVID-19.

In line with the IMIA Yearbook last year's edition [19] on ethics in health informatics, the survey paper of the Clinical Research Informatics (CRI) section authored by Christofidou et al. reviews the publications exploring the European Union's General Data Protection Regulation (GDPR) and the implications that have arisen during the COVID-19 outbreak [20]. The authors call for the creation of a unified and harmonised network or database to enable the secure sharing of data across borders.

The survey paper of Bioinformatics and Translational Informatics (BTI) by McGrath et al. provides an overview of the emerging themes and notable papers published in 2020 [21]. The literature search identified 263 relevant papers in which they examined the central themes of COVID-19, machine learning (representation, interpretation, data security, privacy, and bias concerns), and bioinformatics (drug development, biobanking, and genomic diversity). The survey synthesises work that addresses the most important challenges related to the pandemic, under-representation bias, or high-throughput multi-omics integration.

In this $30^{\text {th }}$ edition of the IMIA Yearbook, you will find valuable contributions from IMIA Working Groups related to the significant topic of COVID-19 (to name 
a few: telehealth, open technology, FAIR requirements, public health data sharing, digital technologies...) showing how health informatics can respond to pandemics and infodemics, but also the Research and Education paper by Hripcsak et al. which focuses on the value of open science in addressing reproducibility of results in COVID-19 research [22].

Make sure to read the International Academy of Health Sciences Informatics (IAHSI) paper (and the personal note) by Dr. Reinhold Haux, the first Academy's and outgoing President [23]. Dr. Haux recalls that IAHSI and IMIA are institutions whose members are willing to "collaborate in a tolerant, collaborative, and peaceful manner, transcending nations, cultures, religions, gender, and political or social structures" with the aim "to contribute to the health and well-being of the people in our world" [24].

In this line, the outgoing IMIA President, Sabine Koch, shares her experience of leading IMIA during a global pandemic, without any physical meetings [25]. She details some new opportunities for our discipline, and introduces the IMIA Academy's open dialogue with the World Health Organization (WHO) Director General, Dr. Tedros Adhanom Ghebreyesus on the challenges of health informatics during the COVID-19 pandemic. The dialogue involved 200 participants from different civil society organizations [26]. Topics of interest were ethics and artificial intelligence, the digital divide, education, and others. Proposed actions included the development of a roadmap based on the lessons learned from the COVID-19 pandemic.

After the 2021 edition of the IMIA Yearbook on managing pandemics through health informatics, it was obvious to choose the 2022 special topic of the Yearbook to be: "Inclusive Digital Health: Addressing Equity, Literacy, and Bias for Resilient Health Systems". As pointed out by McGrath et al., biases in biomedical data limit our understanding of diseases and contribute to a higher morbidity and mortality for minority populations [20]. Moreover, global warming and climate change will have serious implications for the incidence of diseases and the equitable distribution of healthcare. This topic [27] is supported by IMIA Working
Groups and the Yearbook editorial team, and is linked to the call to action of the previous IMIA President, Chris Lehmann [28], to address the complex socio-economic, political, and technological disruptions, as well as the many ethical challenges, that a global pandemic presents.

\section{Changes in the Yearbook Editorial Team}

The Yearbook editorial team was partly renewed in 2019. First, after four years as a chief editor (2012-2016), and four years as IMIA VP Services (2016 - 2020), Brigitte Séroussi MD, PhD, FIAHSI, FACMI, left the Yearbook Editorial Committee on December 2020 and passed the torch to Lina Soualmia, elected at the IMIA General Assembly as the new IMIA VP Services, after four years serving as a chief editor (2016-2020). We are deeply grateful for the hard work and fabulous leadership we have had from you, Brigitte. Thank you so much, we (will) miss you! Fleur Mougin, Professor of Computer Science at the French National Institute for Health, INSERM, University of Bordeaux (Bordeaux, France), has replaced Lina Soualmia as a chief editor working in tandem with Kate Fultz Hollis. We welcome Fleur as a chief editor of the Yearbook.

We are also pleased to welcome Gayo Diallo, Associate Professor of Computer Science, and Georgeta Bordea, post-doctoral fellow of Medical Informatics, both from the French National Institute for Health, INSERM, University of Bordeaux (Bordeaux, France), as the new section editors of the Public Health and Epidemiology Informatics section. Damian Borbolla, Assistant Professor of Biomedical Informatics at University of Utah (Utah, USA) and Grégoire Ficheur, Professor of Public Health, University of Lille (Lille, France), are the editors of the Decision Support section, and Michelle Hribar, Assistant Professor of Medical Informatics and Clinical Epidemiology at Oregon Health and Science University (Oregon, USA), is the editor of the Human Factors and Organisational Issues section. Congratulations are due to the new section editors. "Change is in the air" and William
Hsu, Associate Professor of Radiological Sciences at University of California (Los Angeles, USA) who served as section editor of the Signal Sensors and Imaging Informatics section from 2016 to 2021 is leaving the editorial team in 2022.

\section{Acknowledgements}

The editors are grateful to Adrien Ugon and Martina Hutter for their help, support, and contribution in the creation of the 2021 edition of the Yearbook.

\section{References}

1. Shen L, Bard JD, Triche TJ, Judkins AR, Biegel JA, Gai X. Rapidly emerging SARS-CoV-2 B.1.1.7 sub-lineage in the United States of America with spike protein $\mathrm{D} 178 \mathrm{H}$ and membrane protein V70L mutations. Emerg Microbes Infect 2021 Dec;10(1):1293-9.

2. Dixon BE and Holmes JH. Managing Pandemics with Health Informatics. Yearb Med Inform 2021:69-74.

3. Reeves JJ, Hollandsworth HM, Torriani FJ, Taplitz R, Abeles S, Tai-Seale M, Millen M, Clay BJ, Longhurst CA. Rapid Response to COVID-19: Health Informatics Support for Outbreak Management in an Academic Health System. J Am Med Inform Assoc Jun 2020;27(6):853-9.

4. Editors of Merriam-Webster. Words We're Watching: 'Infodemic'. Available from: https:// www.merriam-webster.com/words-at-play/ words-were-watching-infodemic-meaning

5. Basit MA, Lehmann CU, Medford RJ. Managing Pandemics with Health Informatics: Successes and Challenges. Yearb Med Inform 2021:17-25.

6. Kulikowski CA. Pandemics: Historically Slow "Learning Curve" Leading to Biomedical Informatics and Vaccine Breakthroughs. Yearb Med Inform 2021:290-301.

7. Staccini P, Lau AYS. Consumer Informatics and COVID-19 Pandemics: Challenges and Opportunities for Research: Findings from the Yearbook 2020 Section on Education and Consumer Health Informatics. Yearb Med Inform 2021:210-8.

8. Wu G, Yang P, Xie Y, Woodruff HC, Rao X, Guiot J, et al. Development of a Clinical Decision Support System for Severity Risk Prediction and Triage of COVID-19 Patients at Hospital Admission: an International Multicentre Study. Eur Respir J.2020 Aug 20;56(2):2001104.

9. Weemaes M, Martens S, Cuypers L, van Elslande J, Hoet K, Welkenhuysen J, et al. Laboratory Information System Requirements to manage the COVID-19 Pandemic: a Report from the Belgian National Reference Testing Center. J Am Med Inform Assoc 2020;27(8):1293-9.

10. Borbolla D, Ficheur G. Clinical Decision Support Systems and Computerized Provider Order Entry: Contributions from 2020. Yearb Med Inform 
2021:172-5.

11. Hackl WO, Hoerbst A. Clinical Information Systems Research in the Pandemic Year 2020. An overview of the CIS Section of the IMIA Yearbook of Medical Informatics. Yearb Med Inform 2021:134-40.

12. Poerner N, Waltinger U, Shütze H. Inexpensive Domain Adaptation of Pretrained Language Models: Case Studies on Biomedical NER and Covid-19 QA. In: Findings of the Association for Computational Linguistics: EMNLP 2020. p. 1482-90.

13. Grabar N, Grouin C. Year 2020 (with COVID): Observation of Scientific Literature on Clinical Natural Language Processing. Yearb Med Inform 2021:257-63.

14. Massoudi BL, Sobolevskaia D. Keep Moving Forward: Health Informatics and Information Management beyond the COVID-19 Pandemic. Yearb Med Inform 2021:75-83.

15. Reeves JJ, Pageler NM, Wick E, Melton GB, Tan G, Clay BJ, Longhurst CA. The Clinical Information Systems Response to the COVID-19 Pandemic. Yearb Med Inform 2021:105-25.

16. Séroussi B, Soualmia LF, Holmes JH. Transforming Data into Knowledge: How to Improve the
Efficiency of Clinical Care? Yearb Med Inform 2017 Aug;26(1):4-6.

17. Verspoor K. The Evolution of Clinical Knowledge during COVID-19: Towards a Global Learning Health System. Yearb Med Inform 2021:176-84.

18. Tilahun B, Gashu KD, Mekonnen ZA, Endehabtu BF, Angaw DA. Mapping the Role of Digital Health Technologies in Prevention and Control of COVID-19 Pandemic: Review of the Literature. Yearb Med Inform 2021:26-37.

19. Séroussi B, Hollis KF, Soualmia LF. Transparency of Health Informatics Processes as the Condition of Healthcare Professionals' and Patients' Trust and Adoption: the Rise of Ethical Requirements. Yearb Med Inform 2020 Aug;29(1):7-10.

20. Christofidou M, Lea N, Coorevits P. A Literature Review on the GDPR, COVID-19 and the Ethical Considerations of Data Protection during a time of Crisis. Yearb Med Inform 2021:226-32.

21. McGrath SP, Benton ML, Tavakoli M, Tatonetti NP. Predictions, Pivots, and a Pandemic: a Review of 2020's Top Translational Bioinformatics Publications. Yearb Med Inform 2021:219-25.

22. Hripcsak G, Schuemie MJ, Madigan D, Suchard MA. Drawing Reproducible Conclusions from Observational Clinical Data with OHDSI. Yearb
Med Inform 2021:283-9.

23. Haux R, Ball MJ, Hersh WR, Huesing E, Kimura M, Koch S, Martin-Sanchez F, Otero P. The International Academy of Health Sciences Informatics (IAHSI): 2020 Report. Yearb Med Inform 2021:8-12.

24. Bylaws of the International Academy of Health Sciences Informatics (IAHSI). Approved by the Academy Plenary on August 25, 2019, and by the IMIA General Assembly on August 26, 2019. Available from: https://imia-medinfo.org/wp/ wp-content/uploads/2018/08/IAHSI-Bylaws-approved-August-2019.pdf

25. Koch S. Leading IMIA through a Global Pandemic. Yearb Med Inform 2021:1.

26. Koch S, Hersh WR, Bellazzi R, Leong TY, Yedaly M, Al-Shorbaji N. Digital Health during COVID-19: Informatics Dialogue with the World Health Organization. Yearb Med Inform 2021:13-6.

27. Maxmen, A. Inequality's Deadly Toll. Nature 2021 April; 592:674-80.

28. Lehmann, CU. President of the International Medical Informatics Association. A Call to Action. Yearb Med Inform 2019 Aug;28(1):1-2. 